\title{
Canopy wetness in the Eastern Amazon
}

\author{
Oliver Binks $^{\mathrm{a}, *}$, John Finnigan ${ }^{\mathrm{a}}$, Ingrid Coughlin ${ }^{\mathrm{a}}$, Mathias Disney ${ }^{\mathrm{b}}$, Kim Calders ${ }^{\mathrm{c}}$, \\ Andrew Burt ${ }^{\mathrm{b}}$, Matheus Boni Vicari ${ }^{\mathrm{b}}$, Antonio Lola da Costa ${ }^{\mathrm{d}}$, Maurizio Mencuccini ${ }^{\mathrm{e}, \mathrm{f}}$, \\ Patrick Meir ${ }^{\text {a, } g}$
}

${ }^{a}$ Research School of Biology, The Australian National University, Canberra, 2601 ACT, Australia

${ }^{\mathrm{b}}$ Dept. of Geography, University College London, London, WC1E 6BT, England

${ }^{c}$ CAVElab - Computational \& Applied Vegetation Ecology, Faculty of Bioscience Engineering, Ghent University, Belgium

${ }^{\mathrm{d}}$ Centro de Geosciências, Universidade Federal do Pará, Belém 66075-110, Brasil

e ICREA, Barcelona 08010, Spain

${ }^{\mathrm{f}}$ CREAF, Cerdanyola del Valles, Barcelona 08193, Spain

${ }^{\mathrm{g}}$ School of Geosciences, University of Edinburgh EH9 3FF United Kingdom

\section{A R T I C L E I N F O}

\section{Keywords:}

leaf wetness

foliar water uptake

Amazon

forest micrometeorology

dew

\begin{abstract}
A B S T R A C T
Canopy wetness is a common condition that influences photosynthesis, the leaching or uptake of solutes, the water status and energy balance of canopies, and the interpretation of eddy covariance and remote sensing data. While often treated as a binary variable, 'wet' or 'dry', forest canopies are often partially wet, requiring the use of a continuous description of wetness. Minor precipitation events such as dew, that wet a fraction of the canopy, have been found to contribute to dry season foliar water uptake in the Eastern Amazon, and are fundamentally important to the canopy energy balance. However, few studies have reported the spatial and temporal distribution of canopy wetness, or the relative contribution of dew to leaf wetness, for forest ecosystems.

In this study, we use two canopy profiles of leaf wetness sensors, coupled with meteorological data, to address fundamental questions about spatial and temporal variation of leaf wetness in an Eastern Amazonian rainforest. We also investigate how well meteorological tower data can predict canopy wetness using two models, one empirical and one that is physically-based.

The results show that the canopy is $100 \%$ dry only for $34 \%$ of the time, otherwise being between $5 \%$ and $100 \%$ wet. Dew accounts for $20 \%$ or $43 \%$ of total annual leaf wetness, and $36 \%$ or $50 \%$ of canopy wetness in dry season, excluding or including dew events that co-occur with rain, respectively. Wetness duration was higher at the top than bottom of the canopy, mainly because of rain events, whilst dew formation was strongly dependent on the local canopy structure and varied horizontally through the canopy. The best empirical model accounted for $55 \%$ of the variance in canopy wetness, while the physical model accounted for $48 \%$ of the variance. We discuss future modelling improvements of the physical model to increase its predictive capacity.
\end{abstract}

\section{Introduction}

Leaf wetness is of interest due to its impact on photosynthesis, epiphyll growth on leaf surfaces, disease propagation, the leaching or uptake of solutes, and the water status and energy balance of canopies (Dawson and Goldsmith, 2018). Recently, interest in the occurrence of leaf wetness in natural systems has increased due to the recognition that foliar water uptake is a widespread phenomenon that may contribute significantly to the water budget of plants and communities (Berry et al., 2019; Binks et al., 2019; Steppe et al., 2018).
Leaf wetness is often described in terms of duration, which ranges from $<2 \mathrm{hrs} \mathrm{day}^{-1}$ in arid climates to $>14 \mathrm{hrs} \mathrm{day}^{-1}$ in wet regions (Alvares et al., 2015; Kim et al., 2010) making it a common condition for leaves (Dawson and Goldsmith, 2018). In addition to climate, the surface properties of leaves also influence wetness (Holder, 2013; Klamerus-Iwan and Błońska, 2018; Rosado and Holder, 2013), with some evidence suggesting that leaf water repellence can be higher in dry environments (Brewer and Nunez, 2007; Holder, 2007). While there is a general tendency for canopy wetness to suppress transpiration due to saturation of the water vapour boundary layer (Alvarado-Barrientos

\footnotetext{
* Corresponding author.

E-mail address: Oliver.Binks@anu.edu.au (O. Binks).
} 
et al., 2014; Aparecido et al., 2016; Reinhardt and Smith, 2008), other effects vary widely across species. Photosynthesis, for example, is commonly affected negatively by leaf wetness (Hanba et al., 2004; Ishibashi and Terashima, 1995), but reports of leaf-level 'wet photosynthesis' range from $-48 \%$ (Aparecido et al., 2017) to $+34 \%$ (Smith and McClean, 1989) relative to 'dry photosynthesis'. Leaf wetness can therefore have a substantial impact on the productivity and energy balance of vegetation (Magarey et al., 2006).

Much research has been invested in detecting and modelling leaf wetness because of its potential impact on pathogen susceptibility and primary productivity, but this has been principally directed towards agricultural systems (Kim et al., 2010). Existing models for predicting leaf wetness, both empirical and physical, typically treat plant canopies as a two dimensional surface, or a single point, that is either wet or dry (Alvares et al., 2015; Sentelhas et al., 2008; Sentelhas et al., 2006; Wichink Kruit et al., 2008). Forests, however, have tall structurally complex canopies that can store relatively large quantities of intercepted water (De Ridder, 2001; Teklehaimanot and Jarvis, 1991) that experience diverse micrometeorological conditions (Kruijt et al., 2000; Shaw et al., 1988), and therefore may not be described adequately as simply wet or dry. This distinction, between a binary or fractional state of canopy wetness, has substantial implications for the way in which canopy wetness is understood and modelled (Aparecido et al., 2016).

Few studies have recorded profiles of leaf wetness in forests (Aparecido et al., 2016) resulting in a lack of information about leaf wetness in complex/tall canopies. Existing models for predicting leaf wetness of crops may represent the top-most leaves of a canopy but are unlikely to represent wetness conditions throughout a forest height profile accurately, especially where leaf area index is large. While heavy rain events rapidly saturate a canopy (De Ridder, 2001), drying occurs differentially throughout the forest profile (Aparecido et al., 2016; Harman and Finnigan, 2008), potentially resulting in large differences in wetness duration throughout the canopy. Additionally, small precipitation events, including dew, may wet only a proportion of the canopy and are consequently also likely to result in a canopy state between wet and dry. Such minor precipitation events are known to contribute to foliar water uptake (Berry et al., 2014; Boucher et al., 1995; Burgess and Dawson, 2004; Eller et al., 2013), and thus may result in non-trivial contributions to growth and carbon acquisition (Binks et al., 2020; Steppe et al., 2018). Therefore, the capacity to model ecosystem functioning may be strongly reliant on an understanding of the spatial and temporal variation in leaf wetness.

While there is much uncertainty around the prediction of future precipitation regimes in the tropics (Feng et al., 2013; Joetzjer et al., 2013; Li et al., 2006), the increase in tropical temperatures is expected to outpace the global average (IPCC, 2013). The Amazon is known to experience frequent cycles of morning fog (Anber et al., 2015), and fog and dew formation are both highly sensitive to temperature and specific humidity (Monteith, 1957), the latter of which is predicted to decrease over continental landmasses (Byrne and O'Gorman, 2018). Moreover, recent evidence suggests that dew may make a significant contribution to dry season water uptake in Amazonian rainforest (Binks et al., 2020). Therefore, dew, while seldom included in hydrological water balance studies or models (Anber et al., 2015), is a potentially important source of water and powerful contributor to the canopy energy budget (Magarey et al., 2006), but little baseline information exists on dew frequency and duration or what proportion of the canopy is commonly wetted by dew. Without such information, the responses of tropical forests to climate change may be challenging to explain mechanistically.

In this study, we make use of two canopy profiles of leaf wetness coupled with meteorological measurements to inform our understanding of spatial and temporal variation of leaf wetness in an Eastern Amazonian rainforest. Specifically, we ask how leaf wetness varies throughout the canopy profile, diurnally and seasonally, and to what extent dew contributes to leaf wetness. Using a plant area-weighted output of leaf wetness sensors we derive the proportion of wet canopy area $\left(P_{\mathrm{w}}\right)$, and use an empirically derived model to test how well meteorological variables, measured from the top of a canopy tower, can estimate the proportion of canopy wetness. Finally, we use a physical model, based on the Penman-Monteith equation and coupled with rainfall data, to estimate canopy water storage as a proportion of the maximum value, and to test how well this compares to $P_{\mathrm{w}}$.

\section{Material and Methods}

\subsection{Study Site}

The study was undertaken in the Caxiuanã National Forest Reserve in the eastern Amazon ( $1^{\circ} 43$ 'S, $\left.51^{\circ} 27^{\prime} \mathrm{W}\right)$. The site is in lowland terra firme rainforest $15-25 \mathrm{~m}$ above river level. The site has a mean temperature of ca. $25{ }^{\circ} \mathrm{C}$, receives $2000-2500 \mathrm{~mm}$ of rainfall annually and has a dry season in which rainfall is $<100 \mathrm{~mm}$ per month between June and November.

\subsection{Data}

Meteorological data, including temperature and humidity (CS215, Campbell Scientific, Utah, USA), rainfall (tipping bucket rainfall gauge; Campbell Scientific), wind speed (Windsonic, Campbell Scientific) and net radiation NR-Lite (Campbell Scientific), were logged at 30 minute intervals using a CR1000 data logger (Campbell Scientific) from the top of the tower at a height of $42 \mathrm{~m}$. Temperature and humidity were also recorded at 2,16 , and $28 \mathrm{~m}$ height, through the canopy profile.

Leaf wetness sensors (LWS, Decagon, Pullman, USA) were used to measure two full vertical profiles of canopy/leaf wetness at heights of $36,34,32,30,28,24,19,14$ and $4 \mathrm{~m}$ from the ground, at 15 minute intervals from November 2016 to November 2018. The wetness sensors, orientated horizontally, were connected to ropes attached to opposite sides of a $40 \mathrm{~m}$ tall canopy tower and were hanging through the canopy at a distance of $1.5 \mathrm{~m}$ from the tower. Thus, each height was represented by a pair of sensors. The data were collected on a CR1000 Campbell Scientific data logger. For detailed instructions on the construction of the leaf wetness sensor rigs and analysis of the data, see the methods article Binks et al. (2020 MethodsX). The leaf wetness data set is available at Mendeley Data (https://doi.org/10.17632/sbrbbn7skn.1).

The forest surrounding the tower is highly heterogeneous in both height and horizontal structure. The height of the topmost leaves of the upper canopy ranges from approximately 25 to $35 \mathrm{~m}$, with an emergent tree, $20 \mathrm{~m}$ away from the tower, at around $50 \mathrm{~m}$ in height. We chose to place the uppermost sensors above the point at which the canopy is closed in order to capture the transition through the upper canopy where the leaf area is densest (Meir et al., 2000). It is worth noting, however, that even the sensors at $40 \mathrm{~m}$ will be affected by the canopy under some conditions due to the turbulent boundary layer (Monteith and Unsworth, 2008). For this reason, we have included the data from all of the leaf wetness sensors in the following analyses. Moreover, we measured two canopy profiles in an attempt to represent horizontal heterogeneity. One of the profiles was in an area of lower leaf area density than the other due to canopy heterogeneity.

\subsection{Identifying rain and dew events in the leaf wetness sensor data}

The leaf wetness sensors give a continuous millivoltage output proportional to surface wetness. Any value above a threshold value indicates that the sensor is wet, thus the effective output is binary, wet or dry. Although the magnitude of the output is not a reliable indicator of how much water is present, dew events have a distinct signal recognisable by a gradual increase in wetness, typically at night, and then a rapid return to the baseline value within an hour or two of sunrise (Fig. 1). In contrast, rain events result in a sudden spike in wetness from the baseline to a maximum value within the space of a single measurement interval, 15 minutes, and return slowly and unpredictably to 

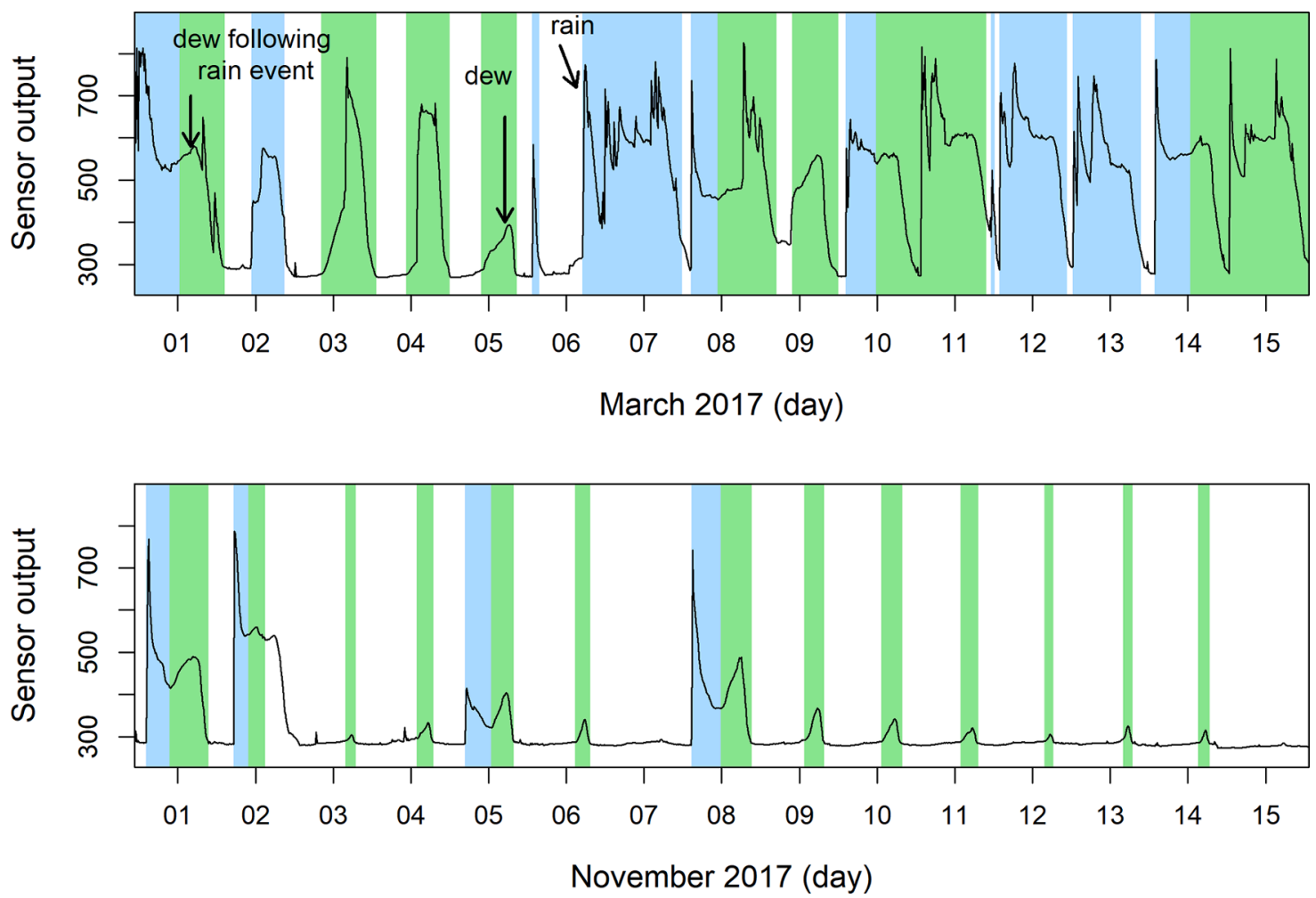

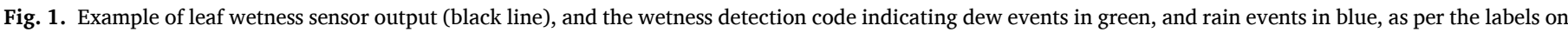

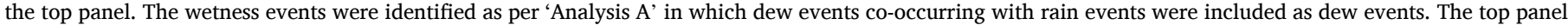
shows wet season and the bottom panel dry season. The line represents a mean of all 18 sensors.

the baseline. Dew events were thus identified from sensor outputs rising continuously for 75 minutes. The advantage of using the gradient to identify a wetting event over using a threshold value is that the baseline value for each sensor is slightly different, and that the baseline value varies over time due to the gradual deposition of detritus on the surface of the sensors. This method was also used to detect the start of rain events (Fig. 1). The sensor value in the time step preceding the start of a precipitation event was taken as a floating threshold, and the end of an event was taken to be the point at which the sensor value fell below the floating threshold. Here we define an 'event' as being the time between the moment at which rain or dew have been detected, to the point at which the sensor is again dry or converts to a different designation (rain or dew). The efficacy of the detection script was assessed by crosschecking the output with a manual inspection of the data in which every time point for each of the sensors was designated either 'rain', 'dew' or 'dry' from five randomly chosen periods of five days. The script used for identifying wetness events is included as SI with the methods article Binks et al. 2020, MethodsX (SI 1 Wetness detection script), and the raw leaf wetness data is in Mendeley Data (https://doi.org/10 .17632/sbrbbn7skn.1).

Dew occurs both as isolated events, and interspersed with rain. This is relevant when considering the proportion of total wetness time that is allocated to rain versus dew. For example, a sensor may already be wet from rain when dew starts to form and, therefore, dew acts to perpetuate wetness initially caused by rain. Because of this, a decision must be taken in the analysis on whether to include dew events that co-occur with rain events (hereafter referred to as 'co-occurring dew events'). As both including and excluding co-occurring dew events provide interesting and relevant information, we did both analyses, Analysis A includes co-occurring dew events, while Analysis B excludes them.

\subsection{Plant area index}

A vertical profile of plant area per volume density was obtained from terrestrial laser scanning (TLS) data, in a field campaign that started on $7^{\text {th }}$ October 2018. TLS data were acquired using a RIEGL VZ-400 instrument (RIEGL, Austria) using an angular sampling resolution of 0.04 degrees and scans were levelled using the on-board inclination sensors. These vertical plant profiles were calculated through estimates of the vertically resolved gap probability in the zenith range 5-70 degrees using 5 degree zenith rings, following the method outlined in Calders et al. (2015) implemented through the python package pylidar (http $: / /$ www.pylidar.org/). TLS data were collected using 36 scan locations in a $20 \mathrm{~m} \mathrm{x} 20 \mathrm{~m}$ regular grid in the same plot as the leaf wetness sensors, and the plot-average vertical plant profile was calculated by averaging the vertically resolved gap fraction of each individual scan location (Cuni-Sanchez et al., 2016).

\subsection{Analysing the wetness data}

The output of each sensor pair represented the total plant area per volume $\left(\mathrm{m}^{2} \mathrm{~m}^{-3}\right)$ between the midpoints of the sensors above and below the pair (Fig. 2), e.g. the sensors at height $32 \mathrm{~m}$ represented the proportion of canopy between 31 and $33 \mathrm{~m}$ because the adjacent sensors were located at 30 and $34 \mathrm{~m}$. The uppermost sensor represented all plant area above $35 \mathrm{~m}$, and the lowest, the plant area below $9 \mathrm{~m}$. The sensors were distributed more closely together at the top of the profile to represent the transition into the densest part of the canopy, and consequently not all sensor pairs represented an equal proportion of plant area index. Each of the nine canopy positions were represented by the average of two sensors. If a sensor pair represented 0.04 of the total plant area index, the possible sensor outputs (as interpreted by the criteria described above) would be ( 0,0 - both sensors dry), $(0,1-$ one sensor wet), or (1,1 - both sensors wet) resulting in a wetness of $0.00,0.02$, or 


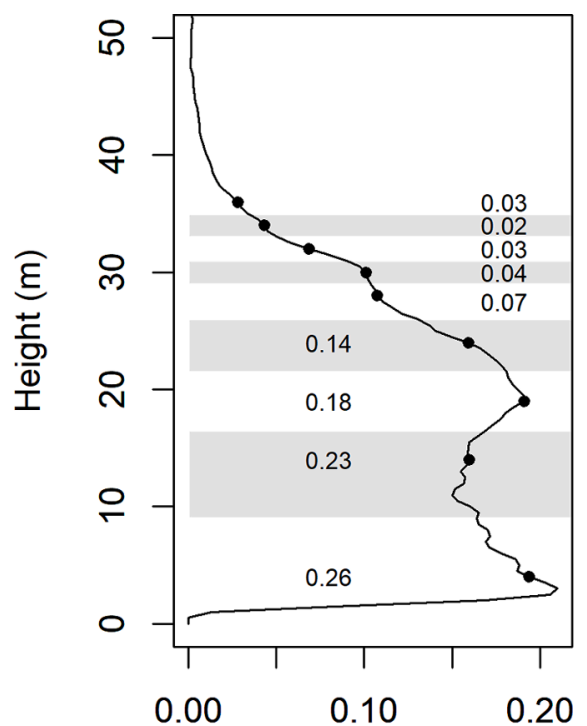

Plant area per volume $\left(\mathrm{m}^{2} \mathrm{~m}^{-3}\right)$

Fig. 2. Vertical profile of plant area per volume derived from terrestrial laser scanning data (black line). The solid points indicate the vertical position of each pair of leaf wetness sensors. The alternate grey white shading, and the corresponding numbers, represent the proportion of plant area, or canopy segment, represented by each sensor pair.

0.04, respectively: hereafter referred to as $S_{\mathrm{x}}$ where $x$ is the sensor position, from 1 to 9 , representing a segment of the canopy. Periodic sensor failure was common due to animals interfering with the wiring and sensors, in which case the output of a single sensor (rather than the average of two) represented the canopy position e.g. (NA,1) = wet, $(\mathrm{NA}, 0)=$ dry. When both sensors at a canopy position failed, the canopy segment would be divided into two, and allocated to the functional sensors above and below the malfunctioning sensor pair, thereby representing the entire canopy with the remaining functional sensors. Time periods in which less than $50 \%$ of the canopy was represented by functional sensors were removed from the analysis.

There are two informative ways to view the wetness data. The proportion of canopy that is wet at a given moment, $P_{\mathrm{w}}=\Sigma\left\{\mathrm{S}_{1(t)}+\mathrm{S}_{2(t)} \ldots+\right.$ $S_{9(t)}$ (where $S_{1(t)}$ is the value of sensor pair ' 1 ' of 9 at time $t$ ), was used to compare the data with the physical and empirical models of canopy wetness, thus the proportional wetness of the entire canopy is represented at each time point. The other way is the proportion of time that a given segment ( $x$, from 1 to 9 ) of the canopy is wet from a specified time period, $P_{\mathrm{t}_{\mathrm{x}}}=\Sigma\left\{\mathrm{S}_{x(t)}+\mathrm{S}_{x(t+1)} \ldots+\mathrm{S}_{x(t+n)}\right\} / n$ (where $n$ is the number of time periods), which was used to determine the relationship between canopy height and mean wetness duration. Over a given time period, the mean $P_{\mathrm{t}}$ of all sensor heights equals the mean $P_{\mathrm{w}}$ from all time steps, $\overline{P_{t(1: 9)}}=\overline{P_{w(t: t+n)}}$, and represents the mean canopy wetness over the period in question. This was used to determine the annual, seasonal and daily means for canopy wetness.

\subsection{Empirical model}

The meteorological variables used in the empirical model were wind speed $(u)$, net radiation $\left(R_{\mathrm{n}}\right)$, temperature $(T)$, relative humidity $(R H)$, and precipitation $(P P)$, Table 1 . All variables were tested for normality using the Shapiro-Wilk test. The variables showing a distribution substantially different from normal $\left(\mathrm{RH}, u\right.$ and $R_{\mathrm{n}}$ ) were then transformed using a Box-Cox power transformation in the $\mathrm{R}(\mathrm{R}$ Development Core Team, 2016) package MASS (version 7.3-50). Precipitation was converted into a two-state factor where the states were $P P>0=$ "rain", and $P P=0=$ "no rain". This was considered preferable to treating rainfall as
Table 1

Meteorological data used in both the physical and empirical models for predicting canopy wetness.

\begin{tabular}{lll}
\hline Symbol & Units & Description \\
\hline$u$ & $\mathrm{~m} \mathrm{~s}^{-1}$ & wind speed \\
$R_{\mathrm{n}}$ & $\mathrm{W} \mathrm{m}^{-2}$ & net radiation \\
$R H$ & $\%$ & Relative humidity \\
$T$ & ${ }^{\circ} \mathrm{C}$ & Temperature \\
$P P$ & $\mathrm{~mm}$ & Precipitation \\
\hline
\end{tabular}

a continuous variable, because values $>0$ clearly resulted in canopy wetting, but values of 0 did not represent any particular state of drying.

Because the empirical model uses continuous variables to predict a proportion $\left(P_{\mathrm{w}}\right)$, we used a beta regression model (Cribari-Neto and Zeileis, 2010). Beta distributions are a diverse family of continuous probability distributions that have an output between (but not including) 0 and 1 . The canopy wetness data contain many zeros and ones, and we therefore initially applied zero- and one-inflated beta regression models (Rigby and Stasinopoulos, 2005). However, these models were substantially more complex, essentially combing three sub-models, and did not perform better than the standard beta regression using a transformed response variable. Thus, following Douma and Weedon (2019) we transformed the response variable, $y=P_{\mathrm{w}}$, such that zeros and ones were fractionally increased and decreased, respectively: $y_{\text {transformed }}=(y(n-1)+0.5) / n$. The initial form of the model contained all variables and interactions and was progressively simplified. In beta regressions the explained variance is represented by the pseudo- $r^{2}$, which is the squared correlation of the linear predictor and the link-transformed response (Cribari-Neto and Zeileis, 2010). The performance of each subsequent model was compared with the initial model using the pseudo- $r^{2}$ in the model output and their AIC values. Because the initial model had the highest pseudo- $r^{2}$ and lowest AIC value of all models, we chose to only present three empirical models: i) all variables and interactions using transformed data, ii) all variables and interactions using untransformed data, and iii) using only $T, R H$ and $P P$ (transformed) as these are most commonly measured meteorological variables. The models will be subsequently referred to as 'transformed', 'untransformed', and 'reduced'. All variable transformations and full model output tables are included in SI.

\subsection{Physical model}

Canopy water storage, $S_{\mathrm{c}}$, is the amount of water retained in the canopy following a precipitation event. When precipitation starts the canopy moves from a dry state to a saturated state, and progresses back to a dry state through evaporation of the surface water on the leaves, stems and branches. The Penman-Monteith model (described below) was used together with precipitation data, to estimate $S_{\mathrm{c}}$ as a proportion of the saturated state, $P_{\mathrm{s}}=S_{\mathrm{c}} / S_{\mathrm{c} \_\max }\left(S_{\mathrm{c} \_\max }=0.2 \mathrm{~kg}_{\text {water }} \mathrm{m}^{-2}\right.$ ground area (De Ridder, 2001)); whereby rain or dew fills up $S_{\mathrm{c}}$ to the saturated state $\left(P_{\mathrm{s}}=1\right)$, that is, the cumulative quantity of precipitation equals or exceeds $S_{\mathrm{c} \_\max }$, and evaporation depletes $S_{\mathrm{c}}$ until the canopy is $\operatorname{dry}\left(P_{\mathrm{s}}=0\right)$ (Teklehaimanot and Jarvis, 1991).

The Penman-Monteith model, or 'combination equation', uses an energy balance approach to estimate sensible and latent heat fluxes from the canopy (Monteith and Unsworth, 2008). The latent heat flux (LE, W $\left.\mathrm{m}^{-2}\right)$, where $L\left(\mathrm{~J} \mathrm{~kg}^{-1}\right)$ is the latent heat of vaporisation of water and $E$ $\left(\mathrm{kg} \mathrm{s}^{-1} \mathrm{~m}^{-2}\right)$ is the rate of evaporation or condensation is given by,

$L E=\frac{s\left(R_{n}-G\right)+\rho c_{p}\left(e_{s}(T)-e_{a}\right) / r_{A}}{s+\gamma\left(1+r_{C} / r_{A}\right)}$

where $s$ is the slope of the saturation vapour pressure curve, $R_{\mathrm{n}}$ is net radiation, $G$ is loss or gain of heat stored in the soil and canopy, $\rho$ is the density of air, $c_{\mathrm{p}}$ is the specific heat of air, at constant pressure and $e_{\mathrm{s}}$ and $e_{\mathrm{a}}$ are saturated and actual vapour pressure (Pa) so that $\left(e_{s}(T)-e_{a}\right)$ is the 
saturation vapour pressure deficit at air temperature $T . \gamma$ is the psychrometric constant and $r_{\mathrm{A}}$ and $r_{\mathrm{C}}\left(\mathrm{s} \mathrm{m}^{-1}\right)$ are respectively, the aerodynamic and canopy resistances to vapour transfer from the leaves to the reference level at which the meteorological variables are measured. This reference level $z_{\text {ref }}$ was at $42 \mathrm{~m}$, which is above the closed part of the upper canopy (Fig. 2). All meteorological variables, constants and other model variables are described in Tables 1 and 2.

$G$ was not measured directly but since diurnal temperature variation was typically less than $10{ }^{\circ} \mathrm{C}$ and the exchange of stored heat in the environment was considered to be much smaller than $R_{\mathrm{n}}$ during daytime, when most evaporation occurs. Hence, $G$ was set to zero in the model.

Equation (1) can be applied to a single leaf or to the entire canopy as in the present case, when it is usually referred to as a single layer or 'big leaf' model (Raupach and Finnigan, 1988). The single layer model treats the 3-D canopy as a 2-dimensional surface or big leaf, represented by single values of meteorological and physiological variables. The canopy resistance $r_{\mathrm{C}}$ describes the resistance to transfer of water vapour from the leaf mesophyll through the stomata to the leaf surface. Since we are interested in evaporation from wet leaves or dew deposition onto the leaves, it is appropriate to set $r_{C}=0$. The aerodynamic resistance $r_{A}$ has two components: a turbulent resistance, $r_{\mathrm{t}}$, to transfer between the notional representative height of evaporation within the canopy $z_{\mathrm{e}}$ and the reference level $z_{\text {ref }}$, (see Table 2 for derivation of $z_{\mathrm{e}}$ ) and a boundary layer resistance $r_{b}$, to transfer from the wet leaf surfaces to $z_{\mathrm{e}}$ so that $r_{A}=$ $r_{t}+r_{b}$. The turbulent resistance was derived using Monin-Obukhov similarity theory (MOST) (Shuttleworth et al., 1984; Tan et al., 2019):

$r_{t}=\frac{\ln \left[\left(z_{\text {ref }}-d\right) / z_{0 m}\right] \cdot \ln \left[\left(z_{\text {ref }}-d\right) / z_{0 H}\right]}{\kappa^{2} \cdot u\left(z_{\text {ref }}\right)}$

Where $d$ is the displacement height of the logarithmic wind profile above the canopy, $z_{0 \mathrm{~m}}$ is the aerodynamic roughness length for momentum, $z_{0 \mathrm{H}}$ is the aerodynamic roughness length for heat, $\kappa$ is von Karman's constant $(0.41)$ and $u\left(z_{\text {ref }}\right)$ is the wind speed at the reference height $z_{\text {ref }}$ (Table 2). MOST theory should be modified when applied close to the canopy within the so-called 'roughness sub layer' (Kaimal and Finnigan, 1995). However, since our field data were limited (e.g. we lacked wind speed data at multiple heights within the canopy) we were unable to apply the most appropriate theory, which describes conditions in the uppermost section of the canopy and the roughness sublayer above (Harman and Finnigan, 2007; Harman and Finnigan, 2008). However, equation (2) has been shown to provide a reasonable approximation to the turbulent resistance at multiple tropical forest field sites (Tan et al., 2019).

Each leaf has a boundary layer resistance and these are assumed to act in parallel to control transfer to the inter-canopy airspace at $z_{\mathrm{e}}$, the representative evaporation height within the canopy. The maximum boundary layer resistance for a single representative leaf $r_{b i \_} \max$, was calculated according to Thom (1975),

$r_{b i \_\max }=\frac{v^{1 / 2}}{k \cdot 0.6052}\left(\frac{D}{u\left(z_{e}\right)}\right)^{1 / 2}$

where $v$ is the kinematic viscosity of air, $k$ is the thermal diffusivity of air, $D$ is the characteristic leaf dimension taken to be $0.065 \mathrm{~m}$, and $u\left(z_{\mathrm{e}}\right)$ is the wind speed at $z_{\mathrm{e}}$ (Table 2). This representative individual leaf boundary layer resistance is then combined with all the other leaves in the canopy acting in parallel to give a total boundary layer resistance $r_{b}$, which is inversely proportional to the evaporative surface area of all the leaves (Choudhury and Monteith, 1988; Lhomme, 1988). In our case this varied from 2PAI, (plant area index, Table 2), when the canopy was saturated $\left(s_{\mathrm{c}}=s_{\mathrm{c} \text { max }}\right)$, to 0 when the canopy was completely dry $\left(s_{\mathrm{c}}=0\right)$. Therefore, we calculate $r_{\mathrm{b}}$ at time $t$ as

$r_{b}(t)=r_{b_{-} \max }\left[\frac{S_{c(t-1)}+2 P A I\left(S_{c_{-} \max }-S_{c(t-1)}\right)}{2 P A I \cdot S_{c_{-} \max }}\right]$

Finally we note that the relationship between the big leaf version of the Penman Monteith equation and multi-layer versions, which more accurately represent the variation of biophysical properties through the canopy, contains many subtleties which we have ignored here. Indeed, it has been the focus of much research over decades. See for example Thom

Table 2

Constants and variables used in the physical model for predicting canopy wetness. Superscript numbers in 'Description' column link to citations in table footnote.

\begin{tabular}{|c|c|c|c|}
\hline Symbol & Value/equation & Units & Description \\
\hline$a$ & 0.14 & $\mathrm{~m}^{2} \mathrm{~m}^{-3}$ & Mean plant area per volume integrated over the profile height, derived from TLS data. \\
\hline$c_{\mathrm{d}}$ & 0.25 & - & Drag coefficient ${ }^{1}$. \\
\hline$c_{\mathrm{p}}$ & 1010 & $\mathrm{~J} \mathrm{~kg}^{-1} \mathrm{~K}^{-1}$ & Specific heaty capacity of air. \\
\hline$d$ & $z_{\mathrm{c}}-\beta^{2} L_{\mathrm{c}}=26.1$ & $\mathrm{~m}$ & Displacement height ${ }^{2}$. \\
\hline$D$ & 0.065 & $\mathrm{~m}$ & Effective/characteristic dimension of leaf. \\
\hline$e_{\mathrm{a}}$ & $e_{s} R H / 100$ & $\mathrm{kPa}$ & Actual vapour pressure ${ }^{3}$. \\
\hline$e_{\mathrm{s}}$ & $610.7 \times 10^{7.5 T / 237 T}$ & $\mathrm{~Pa}$ & Saturated vapour pressure ${ }^{3}$. \\
\hline G & 0 & $\mathrm{~W} \mathrm{~m} \mathrm{~m}^{-2}$ & Heat exchange by conduction to the trees and soil. \\
\hline$k$ & $2.141 * 10-5$ & $\mathrm{~m}^{2} \mathrm{~s}^{-1}$ & Thermal diffusivity of air at 25 degrees. \\
\hline$L_{\mathrm{c}}$ & $\left(c_{\mathrm{d}} a\right)^{-1}=35.7$ & $\mathrm{~m}$ & Momentum absorption length ${ }^{1}$. \\
\hline$P A I$ & 5.2 & $\mathrm{~m}^{2} \mathrm{~m}^{-2}$ & One-sided plant area index derived from terrestrial laser scanning data. \\
\hline$P_{\mathrm{s}}$ & $s_{\mathrm{c}} / s_{\mathrm{c} \_\max }$ & - & Output of physical model, representing the proportion of the maximum amount of surface water stored in the canopy. \\
\hline$P_{\mathrm{w}}$ & - & - & Proportional canopy wetness as determined by the leaf wetness sensors. \\
\hline$s$ & 201.6 & $\mathrm{~Pa} \mathrm{~K}^{-1}$ & Slope of the saturated vapour pressure curve over the interquartile range of the temperature data ${ }^{3}$. \\
\hline$s_{\text {c_max }}$ & 0.2 & $\mathrm{Kg} \mathrm{m}^{-2}$ & Maximum canopy water storage per ground area $^{4}$. \\
\hline$u(z)$ & $u\left(z_{c}\right) \cdot e^{\left(z_{e}-z_{c}\right) / 2 \beta^{2} L_{c}}$ & $\mathrm{~m} \mathrm{~s}^{-1}$ & Wind speed at height $z^{5}$ \\
\hline$u\left(z_{\mathrm{c}}\right)$ & $0.7 u\left(z_{\mathrm{ref}}\right)$ & $\mathrm{m} \mathrm{s}^{-1}$ & Wind speed at top of canopy ${ }^{5}$. \\
\hline$v$ & $1.562 * 10-5$ & $\mathrm{~m}^{2} \mathrm{~s}^{-1}$ & kinematic viscosity of air at 25 degrees. \\
\hline$z_{O H}$ & $0.135 z_{0 \mathrm{~m}}$ & $\mathrm{~m}$ & Aerodynamic roughness length of heat transfer ${ }^{6}$. \\
\hline$z_{0 \mathrm{~m}}$ & $z_{\mathrm{c}} / e^{3}$ & $\mathrm{~m}$ & Aerodynamic roughness length of momentum ${ }^{6}$. \\
\hline$z_{\mathrm{c}}$ & 30 & $\mathrm{~m}$ & Canopy height. \\
\hline$z_{e}$ & $d+z_{O m}=27.6$ & $\mathrm{~m}$ & Representative height of evaporation within the canopy \\
\hline$z_{\text {ref }}$ & 42 & $\mathrm{~m}$ & Height of meteorological sensors ${ }^{3}$. \\
\hline$\beta$ & 0.33 & - & Non-dimensional parameter expressing atmospheric stability ${ }^{1}$. \\
\hline$\gamma$ & 640 & $\mathrm{~Pa} \mathrm{~K}^{-1}$ & Psychrometric constant: 0.64 both sides, $1.28 \mathrm{kPa} \mathrm{K}^{-1}$ one side ${ }^{3}$. \\
\hline$\kappa$ & 0.41 & - & Von Karmen constant ${ }^{3}$. \\
\hline$\rho$ & 1.183 & $\mathrm{~kg} \mathrm{~m}^{-3}$ & Density of air. \\
\hline
\end{tabular}

Source: 1. (Harman and Finnigan, 2007), 2. (Bonan et al., 2018), 3. (Monteith and Unsworth, 2008), 4. (De Ridder, 2001), 5. (Harman and Finnigan, 2008), 6. (Tan et al., 2019). 
(1975) or Raupach and Finnigan (1988).

\subsection{Comparing model outputs with data}

The output of the physical model at time $t$ was dependent on the value of $t-1$, and therefore the data had to be continuous for this analysis. Some sections of data were highly intermittent due to the frequent fauna-related interference to the sensors and power supply, and because we chose not to use data in which $<50 \%$ of the canopy area was represented. Consequently, we split the data into six continuous periods, based on data continuity, with an average duration of approximately 2 months each, which represented nearly a full year (344 days) for the analysis and comparison of both the physical and empirical models.

The output of the physical model is in the same form as the data (a range of 0 to 1 ), enabling a direct statistical comparison using a linear regression of the proportion of the canopy that is wet $\left(P_{\mathrm{w}}\right)$ versus the modelled proportion of the maximum amount of water stored in the canopy ( $P_{\mathrm{s}}$, the physical model output), as $P_{\mathrm{w}} \sim P_{\mathrm{s}}$, in which $r^{2}$ represents the variance accounted for by the model.

The pseudo- $r^{2}$ was used to compare the different versions of the empirical models. However, in order to compare the outputs of each the physical and empirical models using the same statistic, data were generated using the coefficients of the beta regression models $\left(P_{\text {mod_- }}\right.$ transformed,$P_{\text {mod_untransformed }}$ and $\left.P_{\text {mod_reduced }}\right)$. These were then compared directly to the measured data as $P_{\mathrm{w}} \sim P_{\text {mod }}$. This allowed the direct comparison of the variance accounted for by the physical and empirical models.

\section{Results}

\subsection{Total canopy wetness}

The wetness detection script had an accuracy of $90 \%$ compared to values detected manually. The most common cause for misidentification appeared to be due to wrongly identifying the end-points of

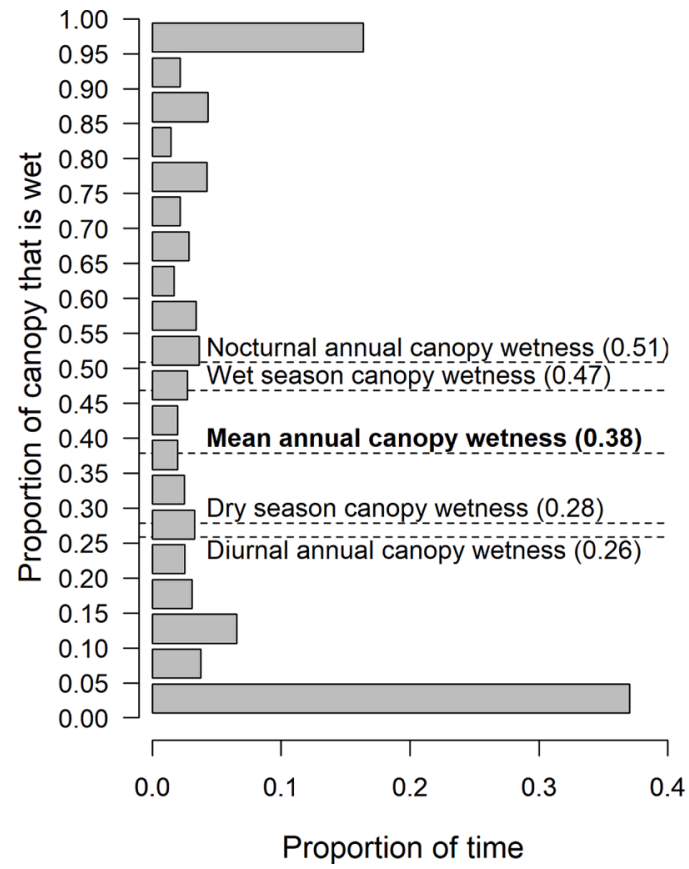

Fig. 3. The proportion of the canopy profile that is wet (binned values from each time point) versus the proportion of time it is wet (the proportion of the total duration of the dataset that the canopy has each binned value), where $y$ axis data is binned in intervals of 0.05 . Dashed lines indicate mean values of canopy wetness for the specified periods.

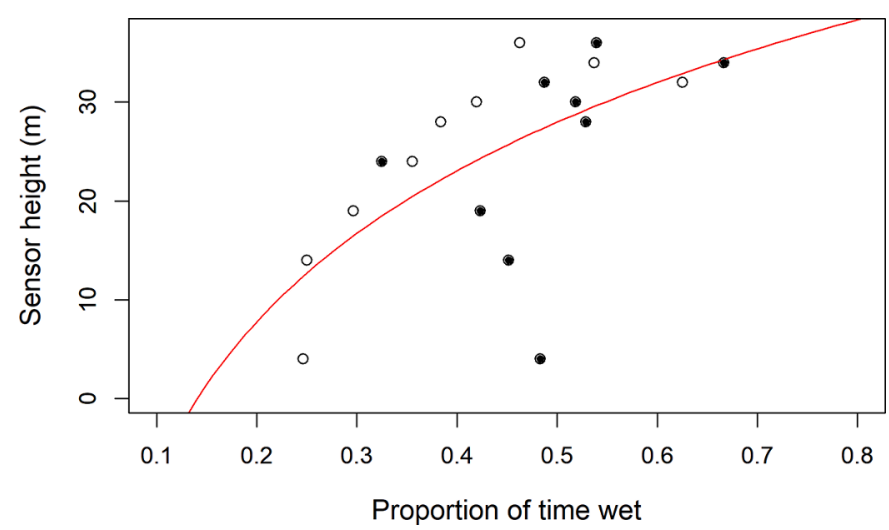

Fig. 4. Relationship between height and wetness: $\mathrm{y} \sim \log (\mathrm{x}) . P<0.01, r^{2}=$ 0.34 . The closed and open circles indicate sensors on different canopy profiles.

precipitation events e.g., the final event in the top panel and the second event in the bottom panel of Fig. 1. Analysis of the proportion of the canopy that is wet $\left(P_{\mathrm{w}}\right)$ versus the amount of time wet, revealed that the canopy is dry ( $<5 \%$ of canopy wet) for $34.4 \%$ of the time, and saturated ( $>95 \%$ of sensors wet) for $15.2 \%$ of the time (Fig. 3). The mean canopy wetness, $P_{\mathrm{w}}$, averaged over all sensors and time-periods, is $38 \%$, and this ranges from $47 \%$ in the wet season to $28 \%$ in the dry season (Fig. 3). There is a significant positive relationship between canopy height and $P_{\mathrm{w}}$ of the form $P_{\mathrm{w}}=e^{(H-a) / b}$, where $H$ is height and $a(43.3)$ and $b$ (22.1) are model coefficients $\left(P=0.006\right.$, and $r_{\text {adj }}^{2}=0.34$, Fig. 4).

\subsection{Dew}

Two analyses were performed on the dew data: one, which included dew events that co-occurred with rain events (as per the labelled event in the top panel of Fig. 1), and another which did not include cooccurring dew events, referred to as Analysis A and Analysis B, respectively. The results of Analysis B will be given in brackets after those of Analysis A.

As a mean from two years of data, the total annual duration of dew

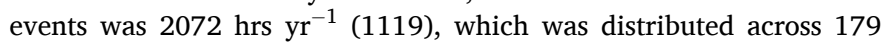
(138) dew events (Table 3 ). The duration of dew events was very variable with a mean of $10.4+/-10.0 \mathrm{hrs}(7.5+/-3.9 \mathrm{hrs})$ where error terms are standard deviation. Dew, as a proportion of the total duration of annual canopy wetness, was $0.43(0.20)$, ranging from $0.40(0.14)$ in the wet season to $0.50(0.36)$ in the dry season, and $0.44(0.19)$ during the day (between the hours of 06:00 and 18:00), and $0.42(0.21)$ at night (Table 4). There was no significant relationship between the proportion of time the sensors recorded dew and the canopy height (Fig. 5, $P=0.71$, $r^{2}<0.01$, or for Analysis B: $P=0.53, r^{2}<0.01$ ), and nor was there a seasonal interaction between dew duration and canopy height. Dew events had significantly shorter duration (and variance in duration) over the dry season months from August to November (Fig. 6).

Table 3

Contribution of dew to leaf wetness from period spanning 8/11/2016 to 8/11/ 2018. Analysis A includes dew that co-occurs with rain (see main text), and Analysis B excludes dew events that co-occur with rain.

\begin{tabular}{lll}
\hline & Analysis A & Analysis B \\
\hline Total hours of dew (mean sensor value) & $2072 \mathrm{hrs} \mathrm{yr}^{-1}$ & $1119 \mathrm{hrs} \mathrm{yr}^{-1}$ \\
Mean canopy wetness during dew event & 0.63 & 0.55 \\
Number of dew events & $179.0 \mathrm{yr}^{-1}$ & $137.5 \mathrm{yr}^{-1}$ \\
Average duration of dew event & $8.0,10.4+/-$ & $6.5,7.5+/-3.9$ \\
$\quad$ (median, mean +/- SD) & $10.0 \mathrm{hrs}$ & $\mathrm{hrs}$ \\
Hours that 100 \% of leaves are wet from dew & $1211.0 \mathrm{hrs} \mathrm{yr}^{-1}$ & $610.6 \mathrm{hrs} \mathrm{yr}^{-1}$ \\
Effective mean length of dew event & $7.6 \mathrm{hrs}$ & $4.4 \mathrm{hrs}^{-}$ \\
\hline
\end{tabular}


Table 4

Proportional contribution of dew to total duration of wetness. Analysis A includes dew that co-occurs with rain, and Analysis B excludes dew events that co-occur with rain.

\begin{tabular}{lll}
\hline & Analysis A & Analysis B \\
\hline Proportion of annual canopy wetness & 0.43 & 0.20 \\
Proportion of dry season canopy wetness & 0.50 & 0.36 \\
Proportion of wet season canopy wetness & 0.40 & 0.14 \\
Proportion of day time wetness (between 06:00 and 18:00) & 0.44 & 0.19 \\
Proportion of night time wetness (between 06:00 and 18:00) & 0.42 & 0.21 \\
\hline
\end{tabular}

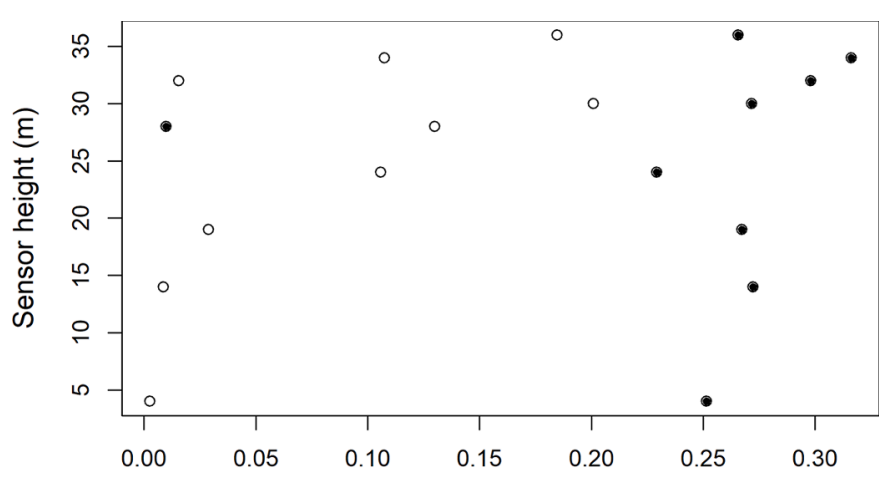

Proportion of time sensors record dew

Fig. 5. Relationship between sensor height and dew formation including dew events co-occurring with rain. No significant relationship $\left(P=0.39, r^{2}=0.05\right)$. The closed and open circles indicate sensors on different canopy profiles.

\subsection{Rain}

In Analysis A, which designates dew events co-occurring with rain events as separate events, there was no significant relationship between duration of wetness attributed to rain and canopy height (linear model, untransformed data, $P=0.13, r^{2}$ adj $=0.08$ ). However, there was a significant relationship when co-occurring dew events were excluded where $P=0.02, r^{2}=0.23$, although excluding an outlier that generated substantial statistical leverage resulted in $P<0.01, r^{2}=0.37$ (Fig. 7).

\subsection{Empirical model}

The beta regressions were all highly significant at $P<<0.001$ (see Table 5 for model description and statistics, and SI 'Empirical model output tables' for all model coefficients). The pseudo- $r^{2}$ and $r^{2}$ indicated that the full model using transformed variables $\left(r^{2} 0.55\right.$, pseudo- $r^{2} 0.42$, AIC -76310) explained a similar amount of the variance than the model using untransformed variables, but had a lower AIC $\left(r^{2} 0.55\right.$, pseudo- $r^{2}$

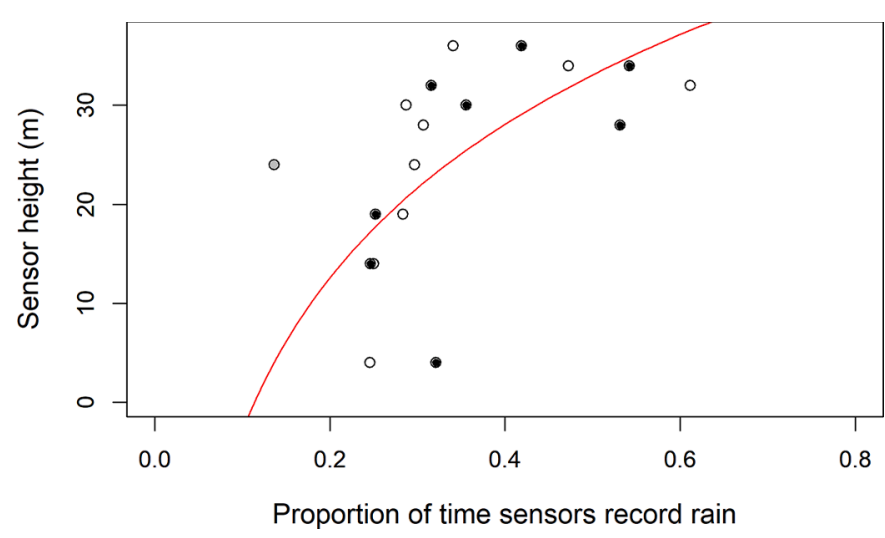

Fig. 7. The proportion of time the sensors are wet from rain, using data from Analysis B in which dew events co-occurring with rain events were excluded. Analysis of the form $y \sim \log (x)$ was preformed excluding the outlier (grey closed circle), $P<0.01, r^{2}$ adj $=0.37$, and including the outlier, $P=0.03, r^{2}$ adj $=$ 0.22 . The red line is fit of the model excluding the outlier. The closed and open circles indicate sensors on different canopy profiles.

Table 5

Empirical models (beta regressions), with, $r^{2}$, pseudo-r ${ }^{2}$ and AIC values. The $r^{2}$ values describe the fit between the proportional canopy wetness $\left(P_{\mathrm{w}}\right)$ and the values generated from the coefficients of each of the models specified below. All models had $P$ values $<<0.001$. Variables with subscript ' $t$ ' are transformed: Temperature $(T)$, relative humidity $(R H)$, wind speed $(u)$, net radiation $\left(R_{\mathrm{n}}\right)$, and precipitation $\left(P P_{\text {factor }}\right)$ represented as a factor where $P P>0=$ 'rain', and $P P=0$ $=$ 'no rain'.

\begin{tabular}{lllll}
\hline Name in text & Model Variables & $r^{2}$ & Pseudo- $r^{2}$ & AIC \\
\hline Transformed & $T, R H_{\mathrm{t}}, u_{\mathrm{t}}, R_{\mathrm{n}_{\_}}, P P_{\text {factor }}$ & 0.55 & 0.42 & -76310 \\
Untransformed & $T, R H, R_{\mathrm{n}}, P P_{\text {factor }}$ & 0.55 & 0.42 & -76295 \\
Reduced & $T, R H_{\mathrm{t}}, P P_{\text {factor }}$ & 0.47 & 0.37 & -74837 \\
\hline
\end{tabular}

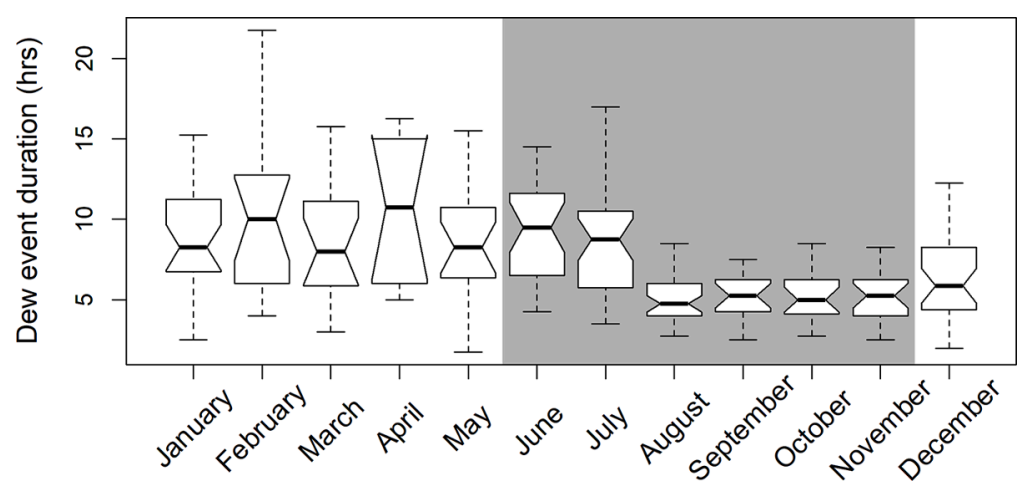

Fig. 6. Duration of dew events per month taken from Analysis B (in which dew events that co-occur with rain are excluded). Grey area represents dry season. The notches in the sides of the boxes give an approximate $95 \%$ confidence interval and, therefore, non-overlapping notches suggest a significant difference between boxes. 

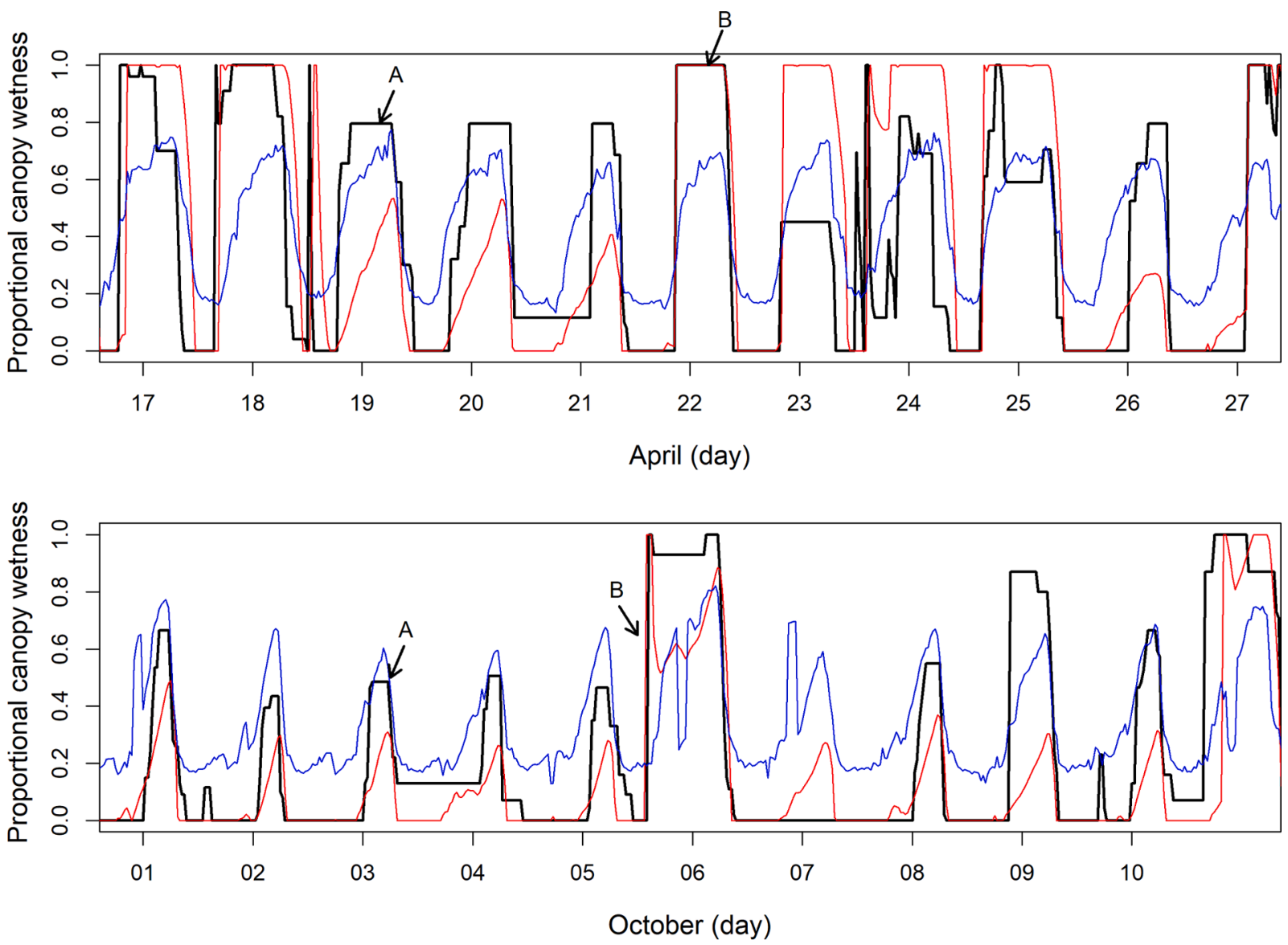

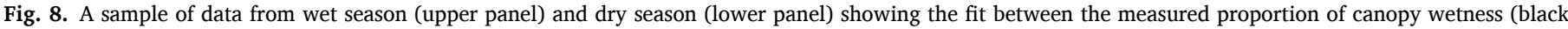

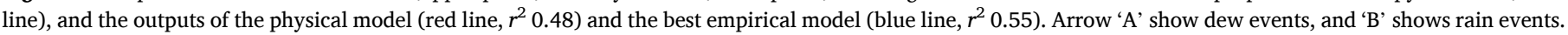

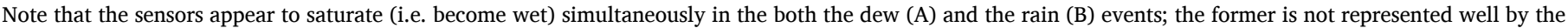

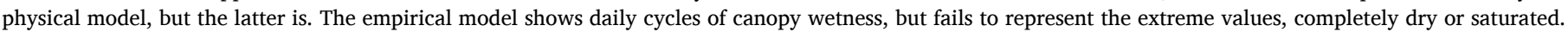

0.42, AIC -76295). The AIC selection procedure indicated that none of the interactions or variables could be removed without significantly reducing the fit of the model. The reduced model, using only temperature, humidity and precipitation, explained the least variance and had the highest AIC value $\left(r^{2} 0.47\right.$, pseudo- $r^{2} 0.37$, AIC -74837). To test the potential predictive capacity of the models, we calculated the percentage of modelled time points that were within 0.05 of $P_{\mathrm{w}}$, where: transformed $=11.2 \%$, untransformed $=11.0 \%$, and reduced $=10.2 \%$.

\subsection{Physical model}

A linear model comparing $P_{\mathrm{s}}$ (the output of the physical model) with the proportion of canopy that was wet, $P_{\mathrm{w}}$, yielded the following results: $P<<0.001, r^{2}=0.48$, slope $=0.77$, and the intercept $=0.08$ (Fig. 8). $38 \%$ of modelled time points were $+/-0.05$ of $P_{\mathrm{w}}$.

A perfect fit would yield a slope and intercept of 1 and 0 , respectively. A slope $<1$ indicates that the modelled $S_{\mathrm{c}}$ is not filling up as quickly as the leaf wetness sensors are saturating $\left(P_{\mathrm{w}}=1\right)$ e.g. the dew events in Fig. 8, but an intercept $>0$ suggests that the canopy storage is often $>0$ when all of the sensors are dry. In other words, the sensor outputs appear to be more binary than the physical model estimates of $S_{\mathrm{c}}$.

\section{Discussion}

\subsection{Leaf wetness}

The results indicate that leaf wetness in a rainforest cannot be simply described in terms of a wetness duration, as $50.4 \%$ of the time the canopy is between 5 and $95 \%$ wet, and the canopy is only completely dry for $34 \%$ of the time (Fig. 3). This has significant implications for interpreting eddy covariance fluxes (Hong et al., 2014; van Dijk et al., 2015) and satellite-derived measurements of canopy moisture content (Konings et al., 2017; Ustin et al., 2012). In contrast to the results of Aparecido et al. (2016), the analysis suggested that leaves at the top of the canopy spend more time wet than those at the bottom (Fig. 4) although, perhaps counterintuitively, not because of dew-related wetness which was variable throughout the canopy profile (Fig. 5), but because of rain (Fig. 7). The two 'rigs' of sensors were installed either side of a tower: one of the rigs was in an area of relatively low canopy leaf area density, while the other was in an area of higher canopy density. All of the sensors that were wet from dew $>20 \%$ of the time (Fig. 5) were on the low canopy density rig, revealing the impact of horizontal canopy structure on dew formation in the lower region of the forest profile. Thus, while our data show no statistical relationship of dew formation with height, we are unable to rule out that measuring more profiles of leaf wetness may reveal some such effect. Alternatively, it is possible that there is no height effect on dew formation as lower diurnal temperature variations at the bottom of the canopy (reducing the occurrence of dew formation) are countered by higher levels of humidity (increasing the occurrence of dew formation). The rain wetness data, on the other hand, shows a consistent height relationship for both rigs, and appears to show a sharp inflection point at around 25 $\mathrm{m}$, above which the proportional time wet increases substantially (Fig. 7). This suggests that the sensors at the top of the canopy are either getting wet more often from very small rain events, or that they are 
taking longer to dry. The former appears more likely as evaporative demand is highest at the top of the canopy (Aparecido et al., 2016). We can infer that these rain events must be smaller than the canopy water storage capacity $(0.2 \mathrm{~mm})$ as the rain does not reach the lowest sensors. Unfortunately, $0.2 \mathrm{~mm}$ is the lower limit of detection for the rain gauge and, therefore, we cannot fully test this hypothesis.

\subsection{Models}

Both the physical and empirical models explained around $50 \%$ of the observed variation in the proportion of canopy wetness (empirical model $r^{2}=0.55$, physical model $r^{2}=0.48$; Table 5, Fig. 8). This is likely to be because of an incomplete representation of the meteorological conditions within the canopy, but also possibly because $P_{\mathrm{w}}$, as determined by the leaf wetness sensors, might not represent the canopy water storage capacity effectively.

The empirical model, using a beta regression, simply showed oscillations of the probability of wetness in line with diurnal fluctuations of $\mathrm{RH}$, temperature and $R_{\mathrm{n}}$. It failed to predict absolute canopy wetness or dryness, but varied consistently between 0.2 and 0.8 . Thus, despite having a higher $r^{2}$ than the physical model, the best empirical model predicted only $11.2 \%$ of the time points correctly $\left(+/-0.05\right.$ of $\left.P_{\mathrm{w}}\right)$ compared to $38.0 \%$ of the physical model.

Because we did not have a profile of net radiation or wind speed, the canopy was represented with average values of meteorological data, thereby treating the forest as a single 'big leaf'. The big leaf, or single layer, model is known to cause biases in the estimation of canopy fluxes due to the heterogeneity of the canopy structure (Luo et al., 2018), and non-linear profiles of meteorological variables (Bonan et al., 2018; Raupach and Finnigan, 1988). However, rain events appear to be quite well represented by the physical model with the drying times appearing to be consistent with that of the leaf wetness sensors (Fig 8, arrows labelled 'B'). Rain events are also the dominant drivers of leaf wetness throughout the year (Table 4, Analysis B).

We used the proportion of wet leaf wetness sensors (weighted by representative canopy area), $P_{\mathrm{w}}$, to represent the proportion of canopy water storage $P_{\mathrm{s}}$. While this may be an effective proxy, these are different concepts potentially confounded by the spatial distribution of water throughout the canopy. The leaf wetness sensors are highly sensitive to the presence of water, thus a minute amount of, e.g. dew, on every sensor would result in $P_{\mathrm{w}}=1$ whereas the actual canopy water storage, $P_{s}$, would be minimal. This is what can be seen in the dew events on $19^{\text {th }}-21^{\text {st }}$ April in Fig. 8 where the sensors saturate quickly, but the modelled flux increases gradually. While this manifests as a limitation to the model as we have presented it, in fact the model output is more likely to be quantitatively accurate, because dew accumulates gradually and not suddenly. This leads to the question of what the functional difference is between the quantity of water stored in the canopy, the leaf area covered by water, and the duration of leaf wetness.

\subsection{Wetness duration, area of leaf wetness, and canopy water storage}

The effects of leaf wetness are very much dependent on duration and specific timing. Our data show that a mean proportion of 0.51 of the canopy is wet at night compared to only 0.26 of the canopy during the day (Fig. 3), resulting in a lower possible impact of leaf wetness on photosynthesis than if wetness was distributed equally over day and night (Berry and Goldsmith, 2020; Reinhardt and Smith, 2008). On the other hand, position is also important here as leaves at the top of the canopy are more photosynthetically active than those at the bottom (Meir et al., 2002), but are also wet for longer periods (Fig. 4). The canopy also appears to dry completely at regular daily intervals, even in the wet season (top panel in Fig. 8), potentially reducing the ris$\mathrm{k} /$ occurrence of fungal infection (Huber and Gillespie, 2003).

Foliar water uptake (FU) can improve plant water status and, consequently, potentially result in increased stomatal conductance and rates of photosynthesis (Berry et al., 2014). Assuming that the rate of FU is not limited by the amount, or rate of formation, of water on the leaf surface, the duration and proportions of leaf area covered are more relevant to calculating canopy-scale FU than the total amount of canopy water storage. However, the rate of uptake, irrespective of the mechanism or pathway, is proportional to the water potential gradient, meaning that one might reasonably expect $\mathrm{FU}$ to occur more rapidly under periods of water stress (Guzmán-Delgado et al., 2018), such as in dry season (Bittencourt et al., 2020). Our results show that the average canopy wetness through the dry season is $28 \%$ (Fig. 3), of which $50 \%$ is accounted for by dew (Table 4, Analysis A), suggesting that a change in the frequency or duration of dew events may have a significant impact on dry season FU.

The total amount of water in the canopy, $S_{\mathrm{c}}$, on the other hand, becomes more important when considering the forest energy budget, but remains relevant for photosynthesis in terms of the impact it has on canopy temperatures (Katul et al., 2012) and water use efficiency (Knauer et al., 2018; Reinhardt and Smith, 2008) during the evaporation of surface water. Day time air temperatures of tropical forest canopies can often exceed the optimal value for canopy photosynthesis (Doughty and Goulden, 2008; Tan et al., 2017) thus, by lowering the canopy and canopy air temperature, the increased evapotranspiration from a partially wet canopy may actually have a positive effect on photosynthesis for a proportion of the leaf area.

\subsection{Dew}

Our data show that dew accounts for a substantial proportion of leaf wetness duration. Dew events that occur independently from rain account for $36 \%$ of the total wetness occurring during dry season (Analysis B, Tables 3 and 4). Dew events occur almost every night when it does not rain (Fig. 1), but become smaller in magnitude and duration as the dry season progresses (Fig. 5). Typically dew dries out by around 08:00 08:30 in wet season (sunrise 06:23) and an hour earlier in dry season (sunrise 05:52), thus the canopy is commonly drying for the first $1-1.5$ hours every morning. Such a regular cycle of wetness is likely to impact productivity by influencing canopy temperatures (Katul et al., 2012), water use efficiency (Knauer et al., 2018), photosynthesis (Reinhardt and Smith, 2008) and foliar uptake (Binks et al., 2020). Some studies suggests that vapour pressure deficit will increase in response to elevated global temperatures (Scheff and Frierson, 2014; Sherwood and Fu, 2014), likely resulting in reduced frequency and duration of dew events, which, given the contribution of dew to canopy wetness, may significantly influence canopy function.

Isolated dew events are easy to detect in the leaf wetness sensor data, but commonly periods of rain are interspersed with dew events, and dew events can be punctuated by rain and drips from higher parts of the canopy. This can make accurate allocation of wetness to either dew or rain challenging over prolonged wetting events. Moreover, because of the definition of an 'event' (the time between rain or dew starting and the point at which the sensor becomes drier than it was at the start of the event), the duration of an event is strongly determined by evaporative demand. This accounts for the large mean and median values for dew event duration (Table 3, Fig. 6). Isolated dew events are interesting because they alter canopy conditions and performance in the absence of rain, but dew events that co-occur with rain appear to account for nearly half of the total duration of dew-induced canopy wetness (Table 2, Analysis A versus B). Therefore, the co-occurrence of dew with rain is likely to increase the total duration of leaf wetness substantially.

While rain saturates the canopy rapidly covering the leaves in a film of water, dew formation occurs as the nucleation of individual droplets (Beysens, 1995) that gradually coalesce at a rate dependent on the surface properties of the leaf (Brewer and Nunez, 2007). Light dew events, such as those seen at the end of dry season (Fig. 1, lower panel), may saturate the leaf boundary layer with water vapour, but probably result in minimal water-leaf contact area. This is likely to have little 
effect on photosynthesis (in terms of light scattering and stomatal occlusion), nutrient leaching, fungal infection or liquid-phase foliar water uptake, but will reduce the canopy temperatures (Katul et al., 2012) and transpiration (Alvarado-Barrientos et al., 2014; Aparecido et al., 2016) during the first hour of daylight almost every morning. Thus, the regular occurrence of dew may result in brief, but regular, windows of high of water use efficiency photosynthesis, or potentially even reverse transpiration (Binks et al., 2020; Vesala et al., 2017).

\subsection{Future research}

Our study design enabled the vertical distribution of leaf wetness to be quantified to some degree, but also revealed the extent to which wetness conditions can vary horizontally due to heterogeneous canopy structure (Figs. 4 and 5). The leaf wetness sensors (LWS) reliably detect moisture, but are only a proxy for leaves which differ in surface properties, orientation, three dimensional shape, and energy balance, and therefore, LWS data must be interpreted in light of these limitations. Ideally, vertical sensor distribution should represent leaf area density; the topmost sensors should be high enough above the canopy to be relatively unaffected by canopy conditions, i.e. fully exposed; and there should be sufficient profiles to enable a spatially averaged vertical value. Finally, it is likely that leaf wetness could be modelled more reliably using a full profile of micrometeorological conditions, particularly wind speed and net radiation.

\section{Conclusion}

Our study shows that wetness in a tropical rainforest canopy cannot be accurately represented as a binary state, but that the canopy is fractionally wet for over $50 \%$ of the time. Leaves at the topmost of the canopy are wet for longer durations than those lower down, but this is likely to be a consequence of very small rain events $(<0.2 \mathrm{~mm})$ rather than dew, which appears to be more influenced by local canopy structure than vertical position. On average, a higher proportion of the canopy was wet at night (51\%) than during the day (26\%), which is relevant in terms of the effect of leaf wetness on photosynthesis. Dew contributes substantially to leaf wetness at this Eastern Amazonian site, both as isolated events, and as perpetuating wetness initially caused by rain. Dew occurred almost every morning and, consequently, a significant portion of the canopy is wet for the first hour of most days.

Our models, physical and empirical, only explained around half of the variance in canopy water storage. This was thought to be largely due to the poor representation of the micrometeorological conditions of the canopy, but also the extent to which the output of the leaf wetness sensors represented the canopy wetness. The results of this study suggest that a multilayer approach to predicting canopy wetness may be substantially more effective than a single layer model for tall, structurally complex vegetation types, providing the profile in canopy conditions can be measured or modelled with sufficient accuracy.

In summary, canopies are wet for a substantial amount of time and we need to understand how canopies function under this common condition in order to represent and predict forest-atmosphere fluxes accurately. There are three limitations to this aim: i) directly measuring the wetness of structurally complex canopies, ii) predicting canopy wetness from meteorological data, and iii) understanding the impact of leaf wetness, and different types of wetness (i.e., film versus droplets), on leaf physiology and fluxes.

\section{Declaration of Competing Interest}

The authors declare that they have no known competing financial interests or personal relationships that could have appeared to influence the work reported in this paper.

\section{Acknowledgements}

This work was supported by: ARC grant DP17010409 to PM; UK NERC grants NE/J011002/1 and NE/N006852/1 to PM and MM; CNPQ grant 457914/2013-0/MCTI/CNPq/FNDCT/LBA/ESECAFLOR to ACLD; EU FP7-Amazalert grant to PM; UK NERC grants NE/N00373X/1 and NE/R016518/1 to MD.

\section{Supplementary materials}

Supplementary material associated with this article can be found, in the online version, at doi:10.1016/j.agrformet.2020.108250.

\section{References}

Alvarado-Barrientos, M., Holwerda, F., Asbjornsen, H., Dawson, T.E., Bruijnzeel, L.A., 2014. Suppression of transpiration due to cloud immersion in a seasonally dry Mexican weeping pine plantation. Agricultural and Forest Meteorology 186, 12-25.

Alvares, C.A., de Mattos, E.M., Sentelhas, P.C., Miranda, A.C., Stape, J.L., 2015. Modeling temporal and spatial variability of leaf wetness duration in Brazil. Theoretical and Applied Climatology 120 (3), 455-467.

Anber, U., Gentine, P., Wang, S., Sobel, A.H., 2015. Fog and rain in the Amazon. Proceedings of the National Academy of Sciences 112 (37), 11473.

Aparecido, L.M.T., Miller, G.R., Cahill, A.T., Moore, G.W., 2016. Comparison of tree transpiration under wet and dry canopy conditions in a Costa Rican premontane tropical forest. Hydrological Processes 30 (26), 5000-5011.

Aparecido, L.M.T., Miller, G.R., Cahill, A.T., Moore, G.W., 2017. Leaf surface traits and water storage retention affect photosynthetic responses to leaf surface wetness among wet tropical forest and semiarid savanna plants. Tree Physiology 37 (10), 1285-1300.

Berry, Z.C., Emery, N.C., Gotsch, S.G., Goldsmith, G.R., 2019. Foliar water uptake: Processes, pathways, and integration into plant water budgets. Plant, cell \& environment 42 (2), 410-423.

Berry, Z.C., Goldsmith, G.R., 2020. Diffuse light and wetting differentially affect tropical tree leaf photosynthesis. New Phytologist 225 (1), 143-153.

Berry, Z.C., White, J.C., Smith, W.K., 2014. Foliar uptake, carbon fluxes and water status are affected by the timing of daily fog in saplings from a threatened cloud forest. Tree Physiol 34 (5), 459-470.

Beysens, D., 1995. The formation of dew. Atmospheric Research 39 (1), 215-237.

Binks, O., Coughlin, I., Mencuccini, M., Meir, P., 2020. Equivalence of foliar water uptake and stomatal conductance? Plant, cell \& environment 43 (2), 524-528.

Binks, O., et al., 2019. . Foliar water uptake in Amazonian trees: Evidence and consequences. Global Change Biology 25 (8), 2678-2690.

Bittencourt, P.R.L., et al., 2020. Amazonia trees have limited capacity to acclimate plant hydraulic properties in response to long-term drought. Global Change Biology n/a (n/a).

Bonan, G.B., et al., 2018. . Modeling canopy-induced turbulence in the Earth system: a unified parameterization of turbulent exchange within plant canopies and the roughness sublayer (CLM-ml v0). Geosci. Model Dev. 11 (4), 1467-1496.

Boucher, J.F., Munson, A.D., Bernier, P.Y., 1995. Foliar absorption of dew influences shoot water potential and root growth in Pinus strobus seedlings. Tree Physiology 15 (12), 819-823.

Brewer, C., Nunez, C., 2007. Patterns of Leaf Wettability along an Extreme Moisture Gradient in Western Patagonia. International Journal of Plant Sciences - INT J PLANT SCI 168, 555-562.

Burgess, S.S.O., Dawson, T.E., 2004. The contribution of fog to the water relations of Sequoia sempervirens (D. Don): foliar uptake and prevention of dehydration. Plant, cell \& environment 27 (8), 1023-1034.

Byrne, M.P., O'Gorman, P.A., 2018. Trends in continental temperature and humidity directly linked to ocean warming. Proceedings of the National Academy of Sciences 115 (19), 4863-4868.

Calders, K., et al., 2015. . Monitoring spring phenology with high temporal resolution terrestrial LiDAR measurements. Agricultural and Forest Meteorology 203, 158-168.

Choudhury, B.J., Monteith, J.L., 1988. A four-layer model for the heat budget of homogeneous land surfaces. Quarterly Journal of the Royal Meteorological Society 114 (480), 373-398.

Cribari-Neto, F., Zeileis, A., 2010. Beta Regression in R. Journal of Statistical Software $34,1-24$.

Cuni-Sanchez, A., et al., 2016. . African Savanna-Forest Boundary Dynamics: A 20-Year Study. PLOS ONE 11 (6), e0156934.

Dawson, T.E., Goldsmith, G.R., 2018. The value of wet leaves. New Phytologist 219 (4), 1156-1169.

De Ridder, K., 2001. Rainwater storage on plant canopies. Journal of Geophysical Research: Atmospheres 106 (D14), 14819-14825.

Doughty, C.E., Goulden, M.L., 2008. Are tropical forests near a high temperature threshold? Journal of Geophysical Research: Biogeosciences 113(G1).

Douma, J.C., Weedon, J.T., 2019. Analysing continuous proportions in ecology and evolution: A practical introduction to beta and Dirichlet regression. Methods in Ecology and Evolution 10 (9), 1412-1430.

Eller, C.B., Lima, A.L., Oliveira, R.S., 2013. Foliar uptake of fog water and transport belowground alleviates drought effects in the cloud forest tree species, Drimys brasiliensis (Winteraceae). The New phytologist 199 (1), 151-162. 
Feng, X., Porporato, A., Rodriguez-Iturbe, I., 2013. Changes in rainfall seasonality in the tropics. Nature Climate Change 3 (9), 811-815.

Guzmán-Delgado, P., Mason Earles, J., Zwieniecki, M.A., 2018. Insight into the physiological role of water absorption via the leaf surface from a rehydration kinetics perspective. Plant, cell \& environment 41 (8), 1886-1894.

Hanba, Y.T., Moriya, A., Kimura, K., 2004. Effect of leaf surface wetness and wettability on photosynthesis in bean and pea. Plant, cell \& environment 27 (4), 413-421.

Harman, I.N., Finnigan, J.J., 2007. A simple unified theory for flow in the canopy and roughness sublayer. Boundary-Layer Meteorology 123 (2), 339-363.

Harman, I.N., Finnigan, J.J., 2008. Scalar Concentration Profiles in the Canopy and Roughness Sublayer. Boundary-Layer Meteorology 129 (3), 323-351.

Holder, C.D., 2007. Leaf water repellency of species in Guatemala and Colorado (USA) and its significance to forest hydrology studies. Journal of Hydrology 336 (1), 147-154.

Holder, C.D., 2013. Effects of leaf hydrophobicity and water droplet retention on canopy storage capacity. Ecohydrology 6 (3), 483-490.

Hong, J., Takagi, K., Ohta, T., Kodama, Y., 2014. Wet surface resistance of forest canopy in monsoon Asia: Implications for eddy-covariance measurement of evapotranspiration. Hydrological Processes 28 (1), 37-42.

Huber, L., Gillespie, T.J., 2003. Modeling Leaf Wetness in Relation to Plant Disease Epidemiology. Annual Review of Phytopathology 30, 553-577.

IPCC, 2013. Climate Change 2013 - The Physical Science Basis: Working Group I Contribution to the Fifth Assessment Report of the Intergovernmental Panel on Climate Change. Cambridge University Press, Cambridge.

Ishibashi, M., Terashima, I., 1995. Effects of continuous leaf wetness on photosynthesis: adverse aspects of rainfall. Plant, cell \& environment 18 (4), 431-438.

Joetzjer, E., Douville, H., Delire, C., Ciais, P., 2013. Present-day and future Amazonian precipitation in global climate models: CMIP5 versus CMIP3. Climate Dynamics 41 (11), 2921-2936.

Kaimal, J.C., Finnigan, J.J., 1995. Atmospheric boundary layer flows-their structure and measurement. Quarterly Journal of the Royal Meteorological Society 121, 1177.

Katul, G.G., Oren, R., Manzoni, S., Higgins, C., Parlange, M.B., 2012. Evapotranspiration: A process driving mass transport and energy exchange in the soil-plant-atmosphereclimate system. Reviews of Geophysics 50 (3).

Kim, K.S., et al., 2010. . Spatial portability of numerical models of leaf wetness duration based on empirical approaches. Agricultural and Forest Meteorology 150 (7), 871-880.

Klamerus-Iwan, A., Błońska, E., 2018. Canopy storage capacity and wettability of leaves and needles: The effect of water temperature changes. Journal of Hydrology 559, 534-540.

Knauer, J., et al., 2018. Towards physiologically meaningful water-use efficiency estimates from eddy covariance data. Global Change Biology 24 (2), 694-710.

Konings, A.G., et al., 2017. . Active microwave observations of diurnal and seasonal variations of canopy water content across the humid African tropical forests. Geophysical Research Letters 44 (5), 2290-2299.

Kruijt, B., et al., 2000. Turbulence Statistics Above And Within Two Amazon Rain Fores Canopies. Boundary-Layer Meteorology 94 (2), 297-331.

Lhomme, J.-P., 1988. A generalized combination equation derived from a multi-layer micrometeorological model. Boundary-Layer Meteorology 45 (1), 103-115.

Li, W., Fu, R., Dickinson, R.E., 2006. Rainfall and its seasonality over the Amazon in the 21st century as assessed by the coupled models for the IPCC AR4. Journal of Geophysical Research: Atmospheres 111 (D2).

Luo, X., et al., 2018. . Comparison of Big-Leaf, Two-Big-Leaf, and Two-Leaf Upscaling Schemes for Evapotranspiration Estimation Using Coupled Carbon-Water Modeling. Journal of Geophysical Research: Biogeosciences 123 (1), 207-225.

Magarey, R.D., Russo, J.M., Seem, R.C., 2006. Simulation of surface wetness with a water budget and energy balance approach. Agricultural and Forest Meteorology 139 (3), 373-381.
Meir, P., Grace, J., Miranda, A.C., 2000. Photographic method to measure the vertical distribution of leaf area density in forests. Agricultural and Forest Meteorology 102 (2), 105-111.

Meir, P., et al., 2002. . Acclimation of photosynthetic capacity to irradiance in tree canopies in relation to leaf nitrogen concentration and leaf mass per unit area. Plant, cell \& environment 25 (3), 343-357.

Monteith, J.L., 1957. Dew. Quarterly Journal of the Royal Meteorological Society 83 (357), 322-341.

Monteith, J.L., Unsworth, M.H., 2008. Principles of environmental physics, Fourth edition, 120. Elsevier, p. 1700. -1700.

R Development Core Team, 2016. RStudio: Integrated Development Environment for R. R Foundation for Statistical Computing.

Raupach, M., Finnigan, J., 1988. 'Single-Layer Models of Evaporation From Plant Canopies Are Incorrect but Useful, Whereas Multilayer Models Are Correct but Useless': Discuss. Functional Plant Biology 15, 705-716.

Reinhardt, K., Smith, W.K., 2008. Impacts of cloud immersion on microclimate, photosynthesis and water relations of Abies fraseri (Pursh.) Poiret in a temperate mountain cloud forest. Oecologia 158 (2), 229-238.

Rigby, R.A., Stasinopoulos, D.M., 2005. Generalized additive models for location, scale and shape. Journal of the Royal Statistical Society: Series C (Applied Statistics) 54 (3), 507-554.

Rosado, B.H.P., Holder, C.D., 2013. The significance of leaf water repellency in ecohydrological research: a review. Ecohydrology 6 (1), 150-161.

Scheff, J., Frierson, D.M.W., 2014. Scaling Potential Evapotranspiration with Greenhouse Warming. Journal of Climate 27 (4), 1539-1558.

Sentelhas, P., et al., 2008. . Suitability of relative humidity as an estimator of leaf wetness duration. Agricultural and Forest Meteorology 148, 392-400.

Sentelhas, P.C., et al., 2006. Evaluation of a Penman-Monteith approach to provide "reference" and crop canopy leaf wetness duration estimates. Agricultural and Forest Meteorology 141 (2), 105-117.

Shaw, R.H., Den Hartog, G., Neumann, H.H., 1988. Influence of foliar density and thermal stability on profiles of Reynolds stress and turbulence intensity in a deciduous forest. Boundary-Layer Meteorology 45 (4), 391-409.

Sherwood, S., Fu, Q., 2014. A Drier Future? Science 343 (6172), 737.

Shuttleworth, W.J., et al., 1984. Eddy correlation measurements of energy partition for Amazonian forest. Quarterly Journal of the Royal Meteorological Society 110 (466), $1143-1162$.

Smith, W.K., McClean, T.M., 1989. Adaptive Relationship Between Leaf Water Repellency, Stomatal Distribution, and Gas Exchange. American Journal of Botany 76 (3), 465-469.

Steppe, K., et al., 2018. Direct uptake of canopy rainwater causes turgor-driven growth spurts in the mangrove Avicennia marina. Tree Physiol 38 (7), 979-991.

Tan, Z.-H., et al., 2017. Optimum air temperature for tropical forest photosynthesis: mechanisms involved and implications for climate warming. Environmental Research Letters 12 (5), 054022.

Tan, Z.-H., et al., 2019. Surface conductance for evapotranspiration of tropical forests: Calculations, variations, and controls. Agricultural and Forest Meteorology 275, 317-328.

Teklehaimanot, Z., Jarvis, P.G., 1991. Direct Measurement of Evaporation of Intercepted Water from Forest Canopies. Journal of Applied Ecology 28 (2), 603-618.

Ustin, S.L., Riaño, D., Hunt, E.R., 2012. Estimating canopy water content from spectroscopy. Israel Journal of Plant Sciences 60 (1-2), 9-23.

van Dijk, A.I.J.M., et al., 2015. Rainfall interception and the coupled surface water and energy balance. Agricultural and Forest Meteorology 214-215, 402-415.

Vesala, T., et al., 2017. Effect of Leaf Water Potential on Internal Humidity and CO(2) Dissolution: Reverse Transpiration and Improved Water Use Efficiency under Negative Pressure. Front Plant Sci 8, 54. -54.

Wichink Kruit, R.J., Jacobs, A.F.G., Holtslag, A.A.M., 2008. Measurements and estimates of leaf wetness over agricultural grassland for dry deposition modeling of trace gases. Atmospheric Environment 42 (21), 5304-5316. 